\title{
FUNCTIONAL EFFECTS OF DECORTICATION AFTER PENETRATING WAR INJURIES TO THE CHEST
}

Nenad Ilić, MD

\begin{abstract}
Decortication was performed in 32 persons with penetrating war injuries to the chest. The indications were acute and chronic post-traumatic empyema, incompletely evacuated hemothorax, chylothorax, and chronic pneumothorax. Decortications were done through a thoracotomy in 29 cases and by thoracoscopy in three cases. Results of overall lung function tests and blood gas analyses were studied in all patients before operation, after immediate postoperative recovery, and 6 months after operation. Significant improvement in lung function was observed after decortication in all patients, particularly after thoracoscopic decortication. Restrictive pattern decreased moderately $(p<0.01)$. Blood gas analyses did not show significant changes after operation. There were no intraoperative or postoperative deaths. (J Thorac Cardiovasc Surg 1996;111:967-70)
\end{abstract}

$P_{\text {i }}$ enetrating war injuries to the chest often result in incompletely evacuated hemothorax and retained foreign bodies, which could lead to posttraumatic empyema (Fig. 1). The incidence of empyema after penetrating war injuries to the chest is higher than after blunt trauma or after other penetrating chest injuries. ${ }^{1-3}$ Factors contributing to establishment of empyema include incomplete expansion of the lung as a result of retained blood, bacterial contamination of blood by penetrating objects, chest tube placement, contagious pneumonia, and hematogenous spread. ${ }^{2}$ Prophylactic antimicrobial administration regularly used in war surgery decreases the incidence of infection of the pleural space. ${ }^{4}$

The manifestations of empyema include malaise, fever, chills, and dyspnea. Radiologic findings show increased pleural density or appearance of air-fluid interfaces. ${ }^{2,3,5}$ Evacuation of the pleural space is the most common treatment in such cases. Chest tube drainage with administration of antimicrobial sometimes suffices. More commonly, decortication either through a thoracotomy or by

From the Thoracic Surgery Department, University Surgical Hospital, Clinical Hospital Split, Split, Croatia.

Received for publication April 13, 1995.

Accepted for publication June 27, 1995.

Address for reprints: Nenad Ilić, MD, Thoracic Surgery Department, University Surgical Hospital, Clinical Hospital Split, Spinčićeva 1, 21000 Split, Croatia.

Copyright (c) 1996 by Mosby-Year Book, Inc.

$0022-5223 / 96 \$ 5.00+0 \quad \mathbf{1 2 / 1 / 6 7 3 8 7}$ thoracoscopy is necessary for adequate evacuation of the infected clot and to free the trapped lung to allow obliteration of the pleural space. ${ }^{6}$ I studied the functional effects of decortication that had to be performed after penetrating war injuries to the chest.

\section{Patients and methods}

During the war in Croatia and Bosnia-Herzegovina, I treated 439 patients with penetrating war chest injuries. I had to perform 32 decortications of the lung, 29 through thoracotomies and three by mearis of thoracoscopy. Indications were infected acute posttraumatic empyema (10), retained foreign bodies (five), incompletely evacuated hemothorax (eight), chylothorax (one), chronic posttraumatic empyema (five), and chronic pneumothorax (three).

Our patients were predominantly male (ratio 30:2) Their average age was 28 years. They were operated on within the period from September 1991 to October 1994. I performed three thoracoscopic decortications within first 10 days after injury. Other decortications were done through thoracotomies within 2 to 5 weeks after injury. Right lung decortication was performed in 18 cases; left lung decortication was performed in 14 cases. The average hospitalization time was 17 days.

The most common postoperative complications were persistent intrapleural effusion (three), atelectasis of a part of the lung (one), and infection of the operative wound (two). All complications were successfully managed by appropriate methods. There were no intraoperative or postoperative deaths.

Overall lung function was analyzed in all patients before operation, after immediate postoperative recovery (5 to 10 days), and 6 months after operation. Spirometric parameters were analyzed on Mijnhardt Vicatest equipment with the CECA (Communiaute Europeenne du Charion et du l'Acier) norms from $1971 .^{7}$ A reduction in vital capacity by $20 \%$ from normal values was considered 


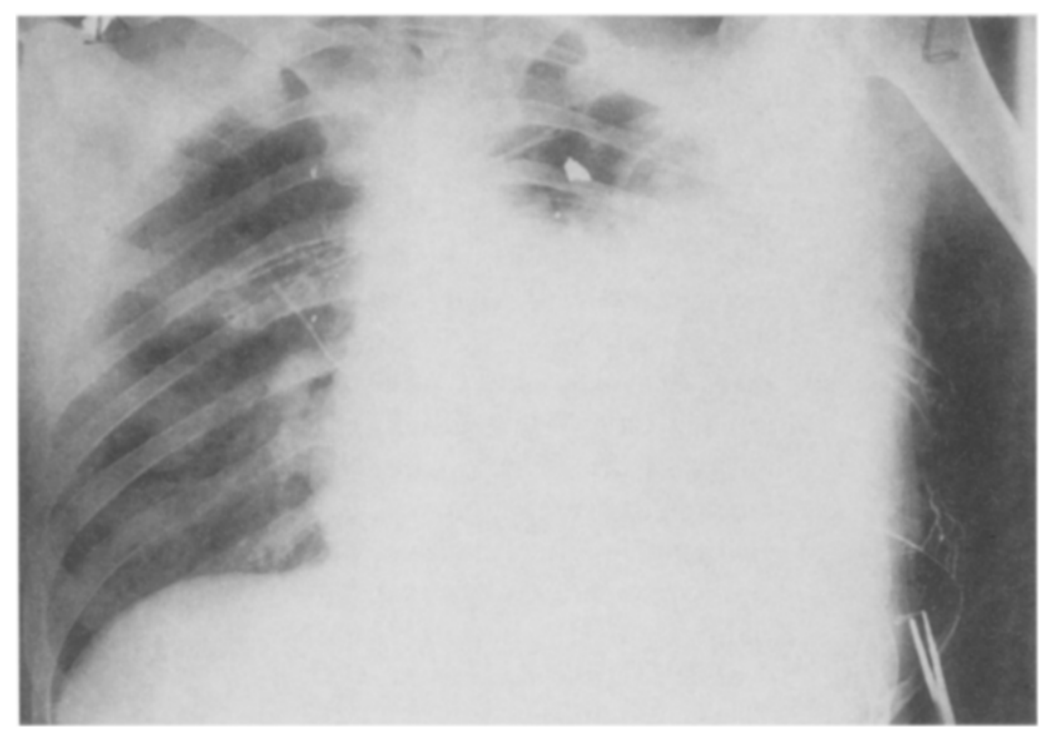

Fig. 1. Chest radiograph of clotted hemothorax after penetrating war injury insufficiently managed by chest tube drainage.

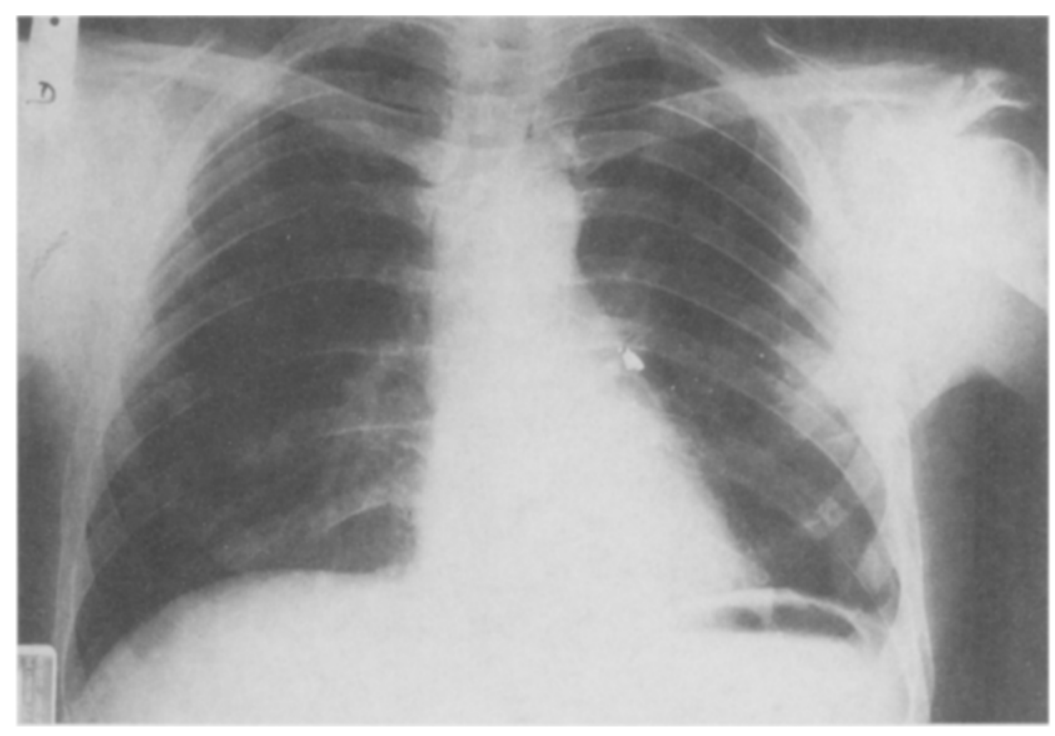

Fig. 2. Chest radiograph of the same patient after decortication of the lung.

to indicate a restrictive disorder of ventilation. Arterial blood gases (ABGs) were analyzed on an ABL 2 type Radiometer (Radiometer Medical A/S, Copenhagen, Denmark). The data were statistically processed by Student's $t$ test at significance levels ranging from 0.01 to 0.05 .

\section{Results}

The main operative goal, evacuation of the infected clot and obliteration of the pleural space, was successfully achieved in all patients (Fig. 2). The vital capacities of injured persons submitted 
to decortication are shown in Table I. There was a medium degree of reduction in vital capacity in most (groups III and IV). Obstructive disorders of ventilation were not observed. ABGs were mostly within normal range, except in six subjects with slight hypocapnia as a consequence of hyperventilation.

The data after decortication through a standard thoracotomy are presented in Table II. It can be seen that there was a slight increase of all spirometric values observed at a significance level of 0.05 ( $p<0.01$ for maximum breathing capacity). Postoperative analysis of ABGs showed a slight increase in oxygen tension and a slight decrease in carbon dioxide tension, both without statistical significance with respect to preoperative values, such as moderately decreased alveoloarterial gradient. The improvement in lung function between the immediate postoperative analysis and the analysis done 6 months later had no statistical significance. As shown in Table III, significant improvement in lung function was seen immediately after thoracoscopic decortication. ABGs did not show any significant changes.

\section{Discussion}

In the current era, the vast majority of penetrating injuries resulting in hemothorax are successfully managed with chest tube drainage. ${ }^{1}$ Original teaching from experiences gained in World War II, Lebanon, and Cambodia border wars has been that decortication for a pneumothorax should be delayed for approximately 6 weeks so that an adequate peel could develop, making pulmonary decortication easier. As antibiotic coverage has become broader and thoracic surgeons have grown more experienced, this time limit has generally been abandoned. ${ }^{8,9}$ Contaminated penetrating war injuries to the chest increase the incidence of sequelae that can be adequately treated only by decortication of the lung. ${ }^{5,8}$ This is confirmed by functional results of decortication. ${ }^{9,10}$ Indications for operation and distribution of patients according to age and sex observed in this retrospective study correspond to those in the literature. ${ }^{2,3}$ Postoperative complications are common with this type of war surgery. ${ }^{1-3}$ All complications were successfully managed.

Before operation, most of our patients (23 of 32 , or $72 \%$ ) had moderately severely restrictive ventilation disorders. After operation these conditions improved to become minor restrictive disorders $(p<0.01$ to 0.05 ). Postoperative analysis of lung function was performed 5 to 10 days after
Table I. Preoperative values of vital capacity

\begin{tabular}{lcrc}
\hline Group & $\begin{array}{c}\text { Reduction } \\
\text { in VC }(\%)\end{array}$ & $N$ & $\%$ \\
\hline I & $<21$ & 1 & 3.1 \\
II & $21-30$ & 4 & 12.5 \\
III & $31-40$ & 13 & 40.6 \\
IV & $41-50$ & 10 & 31.3 \\
V & $51-60$ & 2 & 6.3 \\
VI & $61-70$ & 1 & 3.1 \\
VII & $>70$ & 1 & 3.1 \\
Total & & 32 & 100 \\
\hline
\end{tabular}

operation, after chest tube extraction. ${ }^{10-13}$ Later, lung function was studied after definitive stabilization of respiratory function, 6 months after operation. ${ }^{9,}{ }^{10}$ The data showed a lesser degree of improvement in lung function, not statistically significant, compared with the analysis immediately after operation. The results achieved in our patients after 6 months ranged almost to the lower limits of normal values. ABGs did not show significant improvement after decortication. The moderately decreased alveoloarterial gradients were within the normal range.

Attitudes toward earlier evacuation of the infected clot and obliteration of the pleural space are confirmed by the functional results. I performed three early decortications within 10 days after injury with the thoracoscope. Thoracoscopic decortications were performed after exclusion of possible contraindications, such as a thick peel defined on computed tomographic scan, a retained foreign body, air-fluid levels, or persistent air leakage with a chest tube in place. Because of the small number of patients who underwent early thoracoscopic decortication, the functional improvement afforded by this intervention cannot be statistically evaluated with respect to decortication through a standard thoracotomy.

I could not find data in the literature regarding lung function after decortication as a consequence of penetrating war injuries to the chest. Our data were compared with those from studies done by other authors performed after decortication for blunt trauma and penetrating injuries to the chest. ${ }^{10-12,14-16}$ Our results confirmed that appropriately treated war injuries to the chest had the same functional effects as similar civilian injuries, despite increased risk of infection. ${ }^{12,16}$

Early decortication was successfully performed by thoracoscopy, with significantly improved lung function. I suggest that 2 weeks or longer after injury, decortication through a standard thoracot- 
Table II. Lung function and ABGs before, immediately after, and 6 months after decortication through a standard thoracotomy

\begin{tabular}{lcccc}
\hline & $\begin{array}{c}\text { Before } \\
\text { operation }\end{array}$ & $\begin{array}{c}\text { Immediately after } \\
\text { operation }\end{array}$ & $\begin{array}{c}6 \text { months } \\
\text { later }\end{array}$ & \\
\hline Spirometry $(\%)$ & & & & \\
$\quad$ Vital capacity & $58.8 \pm 20.5$ & $66.5 \pm 15.0$ & $70.1 \pm 14.0$ & 0.05 \\
$\quad$ Forced expiration volume in $1 \mathrm{sec}$ & $59.1 \pm 23.7$ & $65.7 \pm 17.6$ & $68.5 \pm 16.5$ & 0.05 \\
$\quad$ Maximal breathing capacity & $56.8 \pm 12.0$ & $67.3 \pm 9.0$ & $68.6 \pm 8.8$ & 0.01 \\
ABGs & $10.3 \pm 2.0$ & $10.6 \pm 1.7$ & $10.7 \pm 1.8$ & $\mathrm{NS}$ \\
$\quad$ Oxygen tension $(\mathrm{kPa})$ & $4.7 \pm 0.4$ & $4.6 \pm 0.8$ & $4.5 \pm 0.8$ & $\mathrm{NS}$ \\
$\quad$ Carbon dioxide tension $(\mathrm{kPa})$ & $7.36 \pm 0.02$ & $7.38 \pm 0.05$ & $7.38 \pm 0.04$ & $\mathrm{NS}$ \\
pH & $13 \pm 3$ & $11 \pm 6$ & $11 \pm 5$ & $\mathrm{NS}$ \\
Alveolar-arterial oxygen gradient $(\mathrm{kPa})$ & & &
\end{tabular}

Values are mean \pm standard deviation.

Table III. Lung function and ABGs before, immediately after, and 6 months after thoracoscopic decortication

\begin{tabular}{|c|c|c|c|c|}
\hline & $\begin{array}{c}\text { Before } \\
\text { operation }\end{array}$ & $\begin{array}{c}\text { Immediately after } \\
\text { operation }\end{array}$ & 6 months & $p$ \\
\hline \multicolumn{5}{|l|}{ Spirometry (\%) } \\
\hline Vital capacity & $59.9 \pm 10.5$ & $74.6 \pm 12.0$ & $75.8 \pm 11.5$ & 0.01 \\
\hline Forced expiration volume in $1 \mathrm{sec}$ & $60.2 \pm 20.4$ & $73.3 \pm 14.2$ & $74.0 \pm 13.8$ & 0.01 \\
\hline Maximal breathing capacity & $57.1 \pm 9.0$ & $72.8 \pm 9.8$ & $73.0 \pm 8.7$ & 0.01 \\
\hline \multicolumn{5}{|l|}{ ABGs } \\
\hline Oxygen tension $(\mathrm{kPa})$ & $10.4 \pm 2.1$ & $10.7 \pm 1.8$ & $10.8 \pm 1.7$ & NS \\
\hline Carbon dioxide tension $(\mathrm{kPa})$ & $4.6 \pm 0.5$ & $4.5 \pm 0.7$ & $4.4 \pm 0.7$ & NS \\
\hline $\mathrm{pH}$ & $7.36 \pm 0.02$ & $7.38 \pm 0.03$ & $7.39 \pm 0.02$ & NS \\
\hline Alveolar-arterial oxygen gradient $(\mathrm{kPa})$ & $12 \pm 2$ & $12 \pm 1$ & $11 \pm 1$ & NS \\
\hline
\end{tabular}

Values are mean \pm standard deviation.

omy should always be done because of the higher incidence of possible intraoperative or postoperative complications of thoracoscopic decortication in such cases. My efforts tend toward this aim.

I gratefully acknowledge Jadranka Tocilj, $\mathrm{MD}, \mathrm{PhD}$, and Ante Petričević, $\mathrm{MD}, \mathrm{PhD}$, for helpful consultations in preparing this article.

REFERENCES

1. Hix WR. Residua of thoracic trauma. Surg Gynecol Obstet 1984;158:295-301.

2. Panagiotis NS, Gott JP. Delayed sequelae of thoracic trauma. Surg Clin North Am 1989;69:135-42.

3. Windheim K. Pleuraempyem. Chirurgia 1980;51:556-61.

4. Grover FL, Richardson JD, Fewel FG, Aron KV, Webb GE, Trinkle JK. Prophylactic antibiotics in the treatment of penetrating chest wounds: a prospective double-blind study. J Thorac Cardiovasc Surg 1977;74:528-36.

5. Villalba M, Lucas CE, Ledgerwood AM, Asfaw I. The etiology of posttraumatic empyema and the role of decortication. J Trauma 1979;19:414-21.

6. Cosseli JS, Mattox KL, Beall SC. Reevalution of early evacuation of clotted hemothorax. Am J Surg 1984;148:786-90.

7. Cotes JE. Lung function. 4th ed. London: Blackwell Scientific Publications, 1979:246.
8. Zakharia AT. Cardiovascular and thoracic battle injuries in the Lebanon war: analysis of 3000 personal cases. J Thorac Cardiovasc Surg 1985;89:723-33.

9. Fasol R, Zilla P, Irvine S, Oppell V. Thoracoabdominal injuries in combat casualties on the Cambodia border. Thorac Cardiovasc Surg 1988;36:33-6.

10. Horch R, Kroenung G, Westhofen P. Zum Einfluss Lungenverkleinender Eingriffe auf die unmittelbare postoperative Lungenfunktion und deren Beeinflussung durch verschiedene Analgesieformen. Z Erkr Atmungsorgane 1990; 147:113-20.

11. Petro W, Massen D. Regional and global lung function in unilateral fibrothorax after conservative therapy and decortication. Thorac Cardiovasc Surg 1982;30:137-41.

12. Toomes H, Vogt-Moykopf I, Arhendt J. Dekortikation der Lunge aus funktioneller Sicht. Prax Klin Pneumol 1983;37: $342-5$.

13. Glinz W. Diagnostic und Behandlung von Notfallsituationen bei Thoraxveretzungen. Akt Chir 1989;24:219-26.

14. Petro W. Neue Ereanntnisse zur Preoperativen Pulmonalen Funktions diagnostik. Fortschr Med 1986;104:451-4.

15. Le Roy Ladure M, Ranson-Bitker B. Uncertainties in the expected value for forced expiratory volume in one second after surgery. Chest 1986;90:222-8.

16. Swoboda L, Laule K, Beattman H, Hasse J. Decortication in chronic pleural empyema. Thorac Cardiovasc Surg 1990;38: 359-61. 